\title{
Educational Innovation for Teaching and Learning of Chemistry in the Degree of Civil Engineering
}

\author{
Sara García-Salgado, Rosa Dominguéz Gómez, Rosario Torralba Marco*
}

Higher Technical School of Civil Engineering, Polytechnic University of Madrid, Spain

Copyright $(2017$ by authors, all rights reserved. Authors agree that this article remains permanently open access under the terms of the Creative Commons Attribution License 4.0 International License

\begin{abstract}
There is a concern among professionals and teachers of scientific and technological Degrees for the lack of vocations for this type of study. In order to mitigate this problem to some extent, Technical University of Madrid (UPM) and some Educational Innovation Groups, formed by Chemistry teachers, have been worked for some years on the organization of several activities to promote the relation among different educational levels, mainly early High School and University. On the other hand, different teaching materials have been developed in order to encourage the motivation and ease the learning of the basic subjects of the first-year of university studies by the students of UPM, with tools or resources such as Punto de Inicio, OpenCourseWare (OCW), Puesta a Punto, at an institutional level. Furthermore, some Educational Innovation Groups have created audiovisual materials (lab practice videos) and virtual lab practices for the learning of Chemistry, as well as games such as Math-Trivial, Physic-Trivial, Drawing-Trivial and Chemical-Trivial. These tools are available on the Internet, as free access web spaces.
\end{abstract}

Keywords Chemistry, Engineering Studies, Teaching Material, Videos, Games, Virtual Lab Practices, Activities with High School Students

\section{Introduction}

The educational innovation group (EIG) ATANI (Acción Tutorial para Alumnos de las Nuevas Ingenierías - Tutorial Action for Students of New Engineering), from the School of Civil Engineering of Technical University of Madrid (UPM), is formed by teachers of Physics and Chemistry, which are subjects of the first course of the Degree in Civil Engineering. This group was created in 2006 and its aim is to improve the efficiency in the acquisition processes of the learning results by the students.

According to Casado et al. [1], who elaborated a "Catalog of Good Practices" in the Education area, these can be defined as motivating or stimulating activities, in order to improve the students' learning. From this consideration, our EIG has paid special attention to the incorporation of active learning methodologies, taking advantage of the different Learning and Communication Technologies (LCT's), in order to enrich the formative processes of the students.

From the beginning of the activity of this IEG, and taking advantage of the calls that UPM has published to carry out educational innovation projects, the group members have not only developed different educational materials, but also attended different conferences and workshops, highlighting the importance and interest of basic subjects, especially Chemistry, in engineering studies, especially in Civil Engineering.

Chemistry is a basic subject matter for a Graduate in Civil Engineering, since it provides an essential knowledge regarding the composition, properties and transformations of the materials used in infrastructure construction and civil works, which may affect the characteristics of any construction, such as its resistance and durability. However, it is remarkable that most of the students who access the Degree of Civil Engineering, have not considered Chemistry as necessary subject for their studies, so they do not choose this subject in High School (Baccalaureate). Consequently, the initial academic formation of the students that enroll the Degree, and therefore must attend the subject Chemistry of Materials, is generally low, as well as uneven.

From the academic course 2010/11, when the curricula was changed due to the inclusion of the European Higher Education Area (EHEA) [2], the subject has suffered a significant reduction in the number of teaching hours, so currently it is a subject of the Spring semester, instead of the annual subject of the previous curricula. Since the profile of the incoming students have not suffered any modification, teachers have to face a difficult situation, regarding the content of the subject to be taught. It is necessary to explain the most advanced and specific topics for the Degree, which of course requires the knowledge of the most basic aspects of Chemistry.

The subject Chemistry of Materials in current curricula of 
the Degree in Civil Engineering, demands the theoretical and practical knowledge of chemical, physical, mechanical and technological properties of the materials used in construction. In addition, some cross-curricular competencies are assigned to the subject, such as team working and communication skills, use of software as well as LCT's, ability to organize and plan, and commitment to the environment preservation.

In order to evaluate these competencies, and take into account the specific context in which the basic subject Chemistry of Materials is developed, the teaching team must have applied different learning strategies since the implementation of EHEA, i.e. throughout the last five academic courses.

In our opinion, the teamwork may be a good strategy to encourage the knowledge leveling of the incoming students, as well as the acquisition of curriculum and cross-curricular competencies, such as organizing ability and communication skills [3]. On the other hand, the use of LCT's (documents, videos and links published in the virtual course of the subject, the platform Moodle) allows the self-learning of the students, although under a certain teachers' control in the case of first-year students. Thus, the students can access the course documentation and related links (such as Punto de Inicio, OpenCourseWare, Puesta a Punto), as well as self-assessment activities (questionnaires).

The participation of UPM in the OpenCourseWare (OCW) project is materialized in the organization of a free, universal and free access web space, which is used by the teachers as a resource to support their teaching activity [4]. The open publication of these materials of high pedagogical value, created by teachers, is one of the contributions of UPM to the free diffusion of knowledge, as a facet of its commitment to the development of the knowledge society. On the other hand, Punto de Inicio is a learning space for new students at UPM. Since university studies at UPM require a solid foundation of scientific knowledge, this is a self-study and self-assessment web site for the new students, where they will find help to reinforce their knowledge in the areas that have the greatest relationship with the studies they have just enrolled. The educational resources available in Punto de Inicio can be used whenever the students decide, at their own pace and according to their needs, with flexibility and interactivity offered by the Internet. It is available through the platform Moodle, from the enrolment date until the beginning of the lectures. Finally, Puesta a Punto is a web-based initiative with the aim of enriching the formation of UPM community members [5]. In this website, different guides, teachings materials and proposals can be found, in order to improve professional and personal abilities through the learning of techniques and skill development in the most demanded competencies. Thus, it is an original space dedicated to encourage cross-curricular competencies, since they are universally valued in different contexts and therefore are useful to the whole university community.

In the present work, the strategies, teaching tools and materials developed by the teachers of the subject Chemistry of Materials, included in the curricula of the Degree in Civil Engineering, in the first year, are presented. These activities have been carried out during the last seven years of the activity of the EIG ATANI, in order to increase the students' motivation to learn this subject, as well as to ease the acquisition and leveling of the basic knowledge of this subject, to be able cover more specific topics related to the Civil Engineering area, such as corrosion processes, chemistry of the binders used in construction, environmental pollution, etc.

\section{Materials and Methods}

The educational materials developed by the members of the IEG Tutorial Program for Students of New Engineering are described in this section. These materials are intended to ease the learning of the students, as well as to motivate them and awake their interests in the acquisition of knowledge related to science and technology, especially for Chemistry.

\subsection{Videos of Lab Practices}

During the academic courses 2010-11 and 2011-12, several teachers from different IEGs in UPM, developed sixteen videos related to the content of different Chemistry lab practices, in order to use them as a teaching support for theoretical lectures and lab practices of this subject, which is included in the curricula of more than six Degrees of UPM [6]. The following videos were elaborated:

1. Melting point

2. Chemical equilibrium. Effect of temperature on kinetics

3. Distillation of a commercial wine for the determination of its alcoholic strength

4. Distillation of a mixture water/ethanol in a pilot plant

5. Determination of the iron(III) oxide content in a cement

6. Neutralization heat (calorimetric method)

7. Chemical kinetics: Study of the reaction rate

8. Solution preparation and acid-base titrations

9. Separation of the components of a mixture by column chromatography

10. Distillation curve of gasoline

11. Determination of chloride content in water: Mohr method

12. Water hardness

13. Measurement of water hardness

14. Removal of hardness from water

15. Metal corrosion and protection methods

16. Electrolysis of a potassium iodide solution

These videos are available on the Internet [7].

In the specific case of the Degree in Civil Engineering, videos 8 and 15 were used in the Chemistry lab practices. To objectively assess the improvements observed by using videos in the lab practice class sessions, during the 
academic course 2012/13, we developed a survey for both students and teachers. It was observed that the use of audiovisual materials as teaching tools motivate and encourage the students' learning, which impacts on the marks obtained in the lab practices, because of clear improvement that has been found since this kind of materials is used. Furthermore, a decrease in the percentage of students who do not attend the lab practices was observed, which has large impact in decreasing the desertion of the subject. Therefore, the videos constitute a complementary and useful teaching tool, although they certainly do not substitute the students' personal study work [8]. Similar conclusions were drawn by teachers of others Degrees in UPM [9].

\subsection{Chemical Trivial (Quimi-trivial-UPM)}

Based on the board game Trivial, a multidisciplinary game called UPM-Trivial was developed [10]. This teaching material was one of the results of an EI project focused on the development of tools that bring the basic subjects to the students of High School, Baccalaureate and even first year of university studies, since the learning of these subjects at this stage can be hard for the students and it is necessary to support them in this process. This would allow the students to apply their knowledge and abilities to leisure tasks and increase their interests for these basic subjects $[11,12]$.

For this purpose, some games were developed, initially corresponding to the four basic subjects, Mathematics, Physics, Chemistry and Drawing, although afterwards, it was expanded in a second phase, to the subjects of Technology and Biology [10]. Every Trivial was developed from a set of four databases of questions.

Quimi-trivial-UPM is available on the Internet, by introducing a user name and selecting a game level [13]. Questions were prepared with two difficulty levels and four categories were included: basic concepts, equilibrium and electrochemistry, matter structure, and inorganic and organic Chemistry (Figures $1 \& 2$ ).

Later, these resources were translated into English, in order to collaborate with the need to promote the bilingual learning among our students. Thus, the databases corresponding to the four basic subjects, and the board and instructions corresponding to each of the games developed in Spanish version were adapted accordingly, and Math-Trivial, Physic-Trivial, Drawing-Trivial and Chemical-Trivial [14] were developed.

\subsection{The Chemistry Experimentation Virtual Lab in UPM}

Virtual labs are important teaching tools that allow students to perform lab practices whose implementation might be difficult for different reasons, such as high cost and experimental time required, or possible risk for the students.

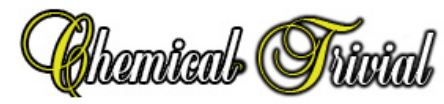

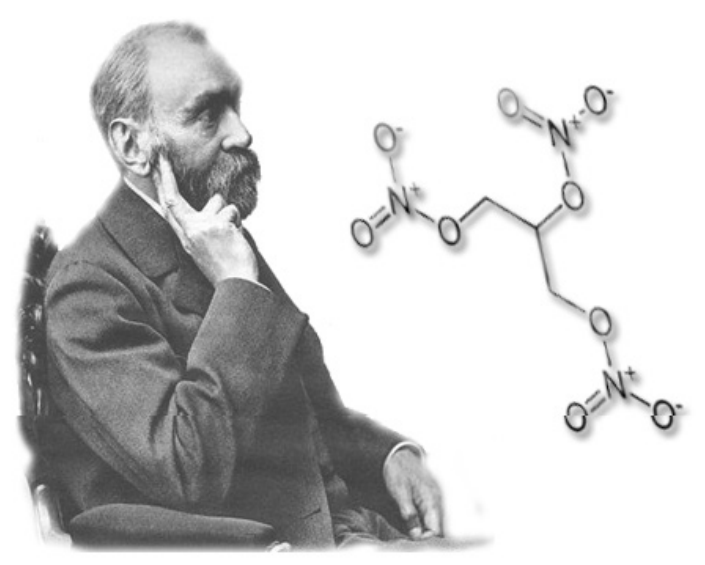

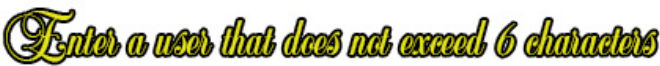

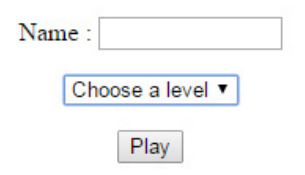

Figure 1. Access screen to Chemical Trivial UPM.

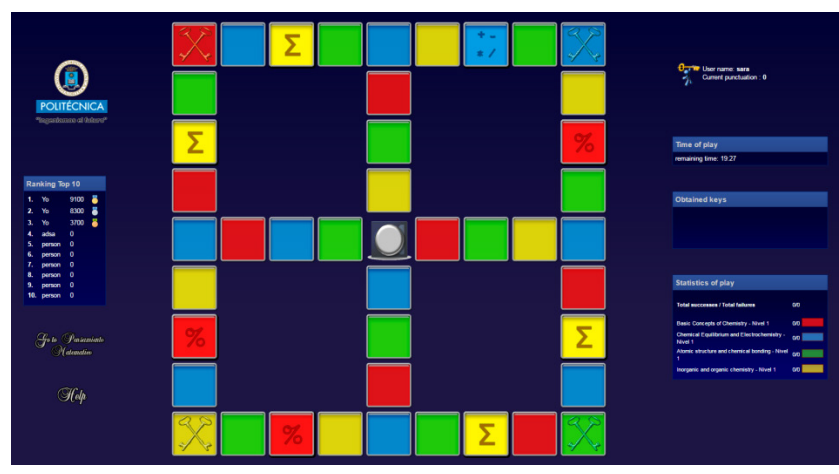

Figure 2. Chemical trivial UPM game board.

The use of a 3D environment, where users manage avatars in a virtual world, emerged in UPM in 2011, as an EI project called "PEIA-UPM: Plataforma de experimentación para los estudios de Ingeniería y Arquitectura de la UPM" (Experimentation platform for Engineering and Architecture studies in UPM). In this project, which was extended during the academic course 2011-2012, several virtual labs were successfully developed: Remote Laboratory of Electronics [15], Agroforestry Biotechnology, Science and Engineering of Materials, and Control of Irrigations. Our EIG ATANI participated in this project with the sub-project IE-105 815 144 [16], for the development of the Chemistry Experimentation virtual lab, which is incorporated in the UPM virtual lab service, managed by the Gabinete de Tele-Educación of UPM (GATE) [17].

The Chemistry Experimentation virtual lab was initially formed by one building, where students can access different 
videos and games, as well as perform basic operations and simple lab experiments. From this setting, the initial aims of this virtual lab were extended, and a lab practice for the determination of metals in polluted soils by sample digestion in a microwave oven and subsequent analysis by ICP-AES was developed. Therefore, it was necessary to adapt the available space to the specific requirements of this virtual lab practice, so two more buildings were created, which in turn distributed in different rooms: one of them is designed for the sample digestion by microwave oven, and the other is for the analysis by ICP-AES. This separation in two buildings tries to reproduce the configuration of a real Chemistry lab, where sample preparation and analysis are usually performed in two different rooms.

To develop this virtual lab practice, it has been necessary to create different types of materials, apparatus and instruments, with many details which give them a most real aspect (Figures $3 \& 4$ ). Students access the virtual world perfectly identified, through an avatar that they must create from a user name and password.

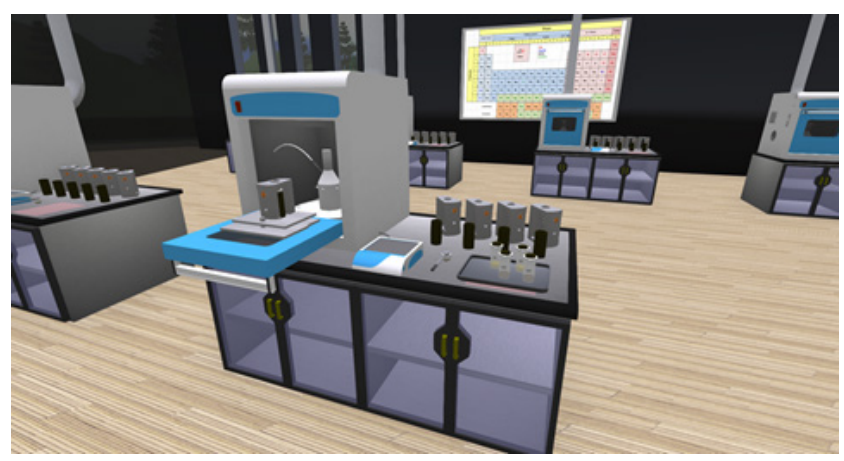

Figure 3. Room 3 of the Chemistry Experimentation virtual lab: Microwave oven and fridge

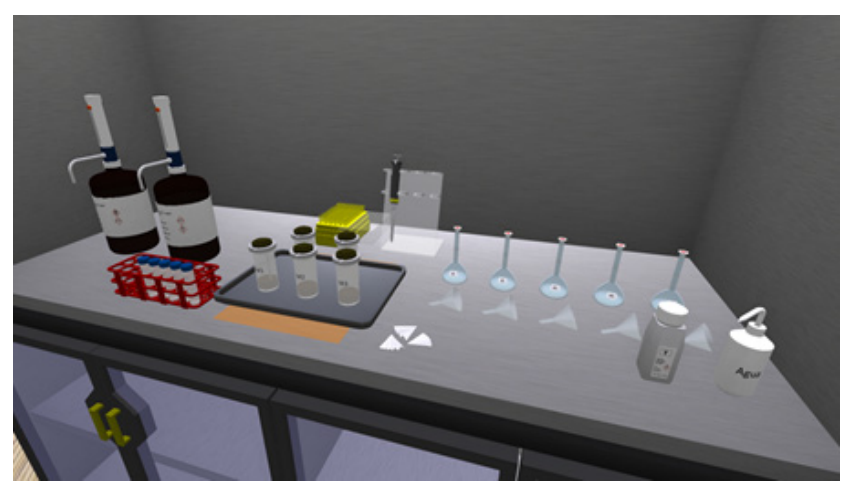

Figure 4. Room 2 of the Chemistry Experimentation virtual lab: Hoods, with the material for sample dilution.

This virtual lab practice was designed to be included in the program of the subject Environmental Science of the Degree in Civil Engineering [18]. It has been used since the academic course 2014/15, always after the realization of a face-to-face lab practice, using the materials and equipment available in the Chemistry laboratory. For the academic courses 2014/15 and 2015/16, students' opinion on virtual lab practice has been collected through surveys, the times used by the students in the realization of the virtual lab practice have been monitored and studied, and the degree of learning acquired by the students in both modes of practice used (face-to-face and virtual) has been evaluated [19]. As general conclusions, most of the students carried out the virtual lab practice for approximately two hours, which is in agreement with the estimation included in the program of the subject Environmental Science, regarding the students' dedication. One of the most valued aspects by the students is the possibility to access the resource at any time of the day, instead of attending a lab practice on a certain day and time, usually fixed by the teacher. However, some negative opinions were also collected, in our opinion due to the students' lack of training in managing the avatar, aggravated by the tendency of certain students to postpone the realization times and task submission until established the deadline. Besides, it was checked that the academic results of the virtual practice were similar to or better than those obtained in the face-to-face practice, despite the greater difficulty of virtual practice, which is in agreement with Brinson [20]. After the experience of these two academic courses, the teachers' opinion regarding the implementation of virtual practices has been very positive, for long time and high cost practices, as well as practices that might represent a certain risk for the students, but always as a complement for face-to-face practices, but of course not as a substitute of them.

\subsection{Workshops with Student of Early High School (Compulsory Secondary Education-ESO in Spain)}

UPM run during the academic course 2014/2015 the transversal EI project "UPM para Jóvenes: una mirada hacia el futuro" (UPM for Youth: a look into the future), which aims at promoting activities among pre-university students to let them discover their own talents and showing them in detail professions related to Civil Engineering and Architecture. Our EIG ATANI participated in this project by the organization of a two-day workshop focusing on "Civil Engineering and Construction" and "Civil Engineering and Infrastructures" with a total of 60 participating students from the $2^{\text {nd }}$ course of the Compulsory Secondary Education (early High School, 13-14 year-old students). Each workshop was aimed at divulging Civil Engineering as a profession and its influence on our daily lives, as well as familiarizing students with basic concepts of the area and challenging them with different tasks and laboratory tests.

Both workshops started with a short talk, presenting how Civil Engineering works have influenced current development and are present in our daily lives. For example, they were shown how engineering makes possible water supply and sanitation at home, or how we can move on highways to school or office. After the talk, students were guided in a visit to the School of Civil Engineering, and they were showed facilities, bibliography for Engineers, Cartography and other resources. At the end, students were 
divided into small groups (4-5 students) and were led to laboratories to carry out different activities and tests with the aid of Civil Engineering volunteer students and supervised by teachers [21].

\subsubsection{Workshop "Civil Engineering and Building"}

During this workshop the following activities were presented and done:

- Preparation of mortar and tensile strength tests.

- Construction of an arch with no binders.

- Construction of a structure of different heights and behavior in an earthquake.

- Observation of concrete degradation by carbonation (atmospheric $\mathrm{CO}_{2}$ ): chemical experiment.

In this last activity, we wanted to highlight the presence and importance of Chemistry in the field of Civil Engineering, in order to make early High School students aware when studying this subject in the pre-university courses.

For this purpose, students were given a series of standard solutions of compounds such as lemon, vinegar, soap, fertilizer and ammonia. They tested the solutions with strips of $\mathrm{pH}$ paper, classifying them into acidic, neutral or alkaline, depending on the color acquired by the indicator paper. Then in a test plate, they poured some of the same solution and added a few drops of phenolphthalein to see the effect in each case (Figure 5). Phenolphthalein is an acid-base indicator that turns pink, more or less intense for substances with a $\mathrm{pH}$ higher than 8.2, while it remains colorless for $\mathrm{pH}$ under this value.

Afterwards students sprayed phenolphthalein solution (1\% $\mathrm{w} / \mathrm{v}$ ethanol) over mortar and concrete specimens, previously manufactured and exposed to atmospheric $\mathrm{CO}_{2}$ for different periods. In the end, differences in coloration among samples were analyzed and discussed relating them to the variation in mortar and concrete properties by the effect of the carbonation process (Figure 6).

\subsubsection{Workshop "Civil Engineering and Infrastructures"}

The activities included in this workshop were the following:

- Construction and testing of articulated bridge structures.

- Sieve analysis.

- Highways: what are they made of?

During the sieve analysis, students conducted a gradation test, determining different diameters of the particles of a soil sample, using sieves of different sizes. This test allowed them to identify different soil types and whether they are suitable for highway construction or not. Afterwards, they performed the activity "Highways: what are they made of?", which was formed by different tasks, some of them very related to Chemistry.

Students were explained that roads are mainly made of bitumen and aggregate. Participants used aggregate fractions sieved in the previous activity for different experiments. They observed the fracture faces of the coarser fraction and performed a methylene blue test to determine the clay content in the fine fraction (Figure 7). Afterwards students analyzed bitumen hardness/brittleness by determining the softening point by "ring and ball" method.

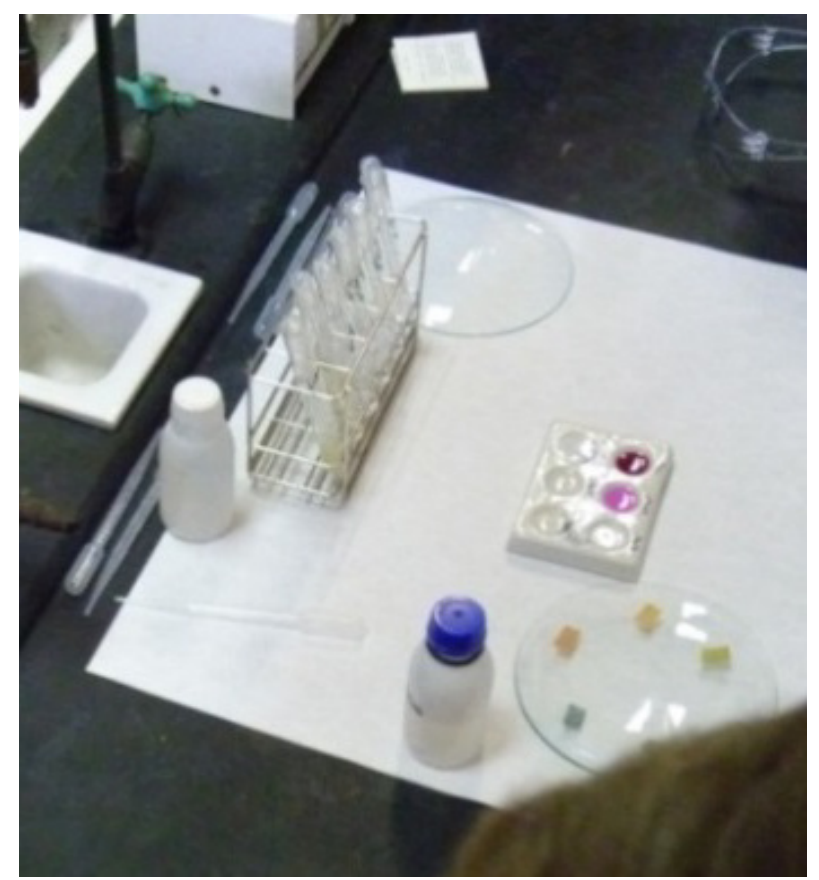

Figure 5. Determination of $\mathrm{pH}$ of several well-known substances.

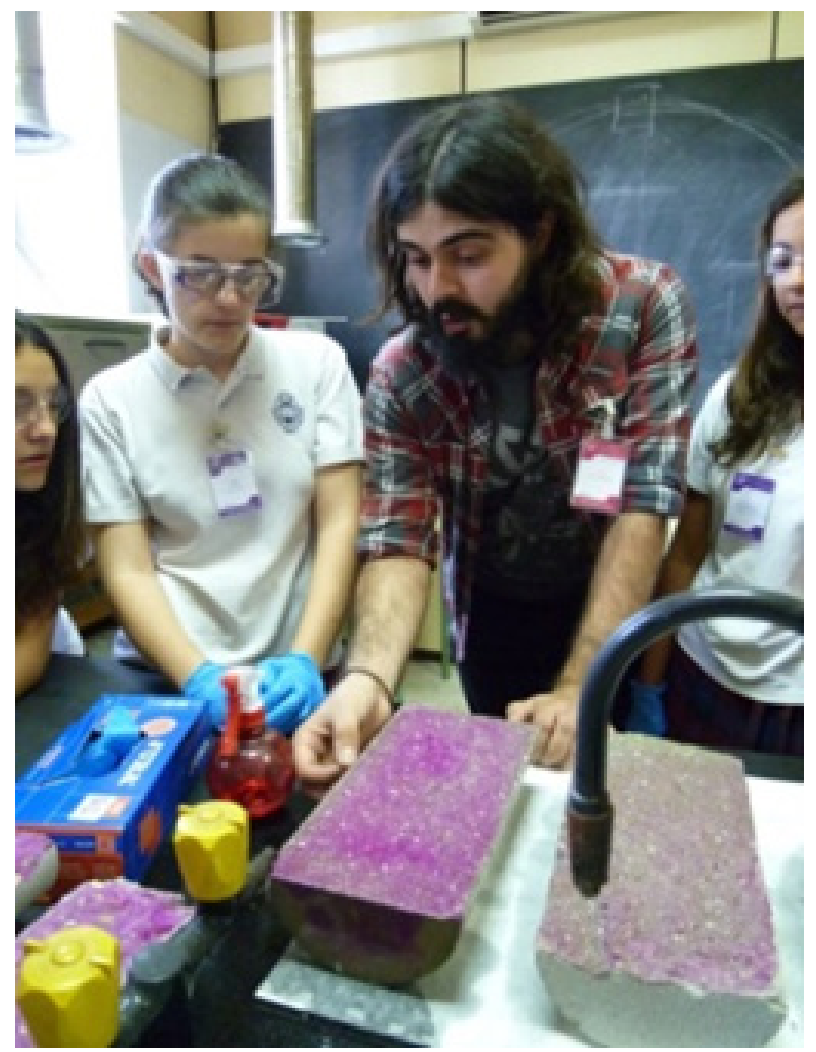

Figure 6. Activities in the Workshop "Civil Engineering and Construction": Degradation of concrete through the carbonation process. 


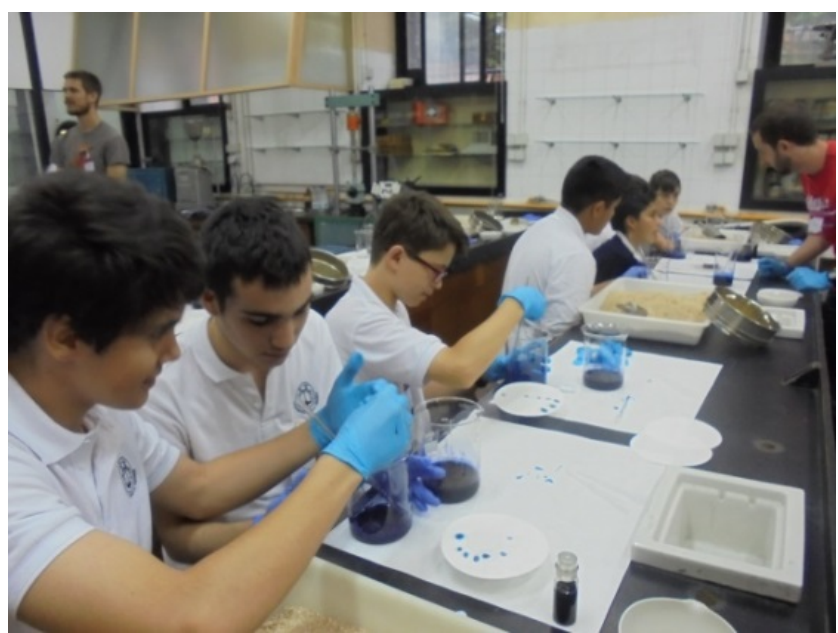

Figure 7. Activities in the Workshop "Civil Engineering and Infrastructures": Methylene blue test for the determination of the clay content in the fine fraction of a soil sample.

\section{Conclusions}

All the activities organized by the University, involving the participation of students from early High School, have a very favorable repercussion on the relation between both educational institutions, since they contribute to the acquaint of the possible future students with the university environment and subjects.

At the same time, the use of information and communication technologies, the development of audiovisual materials and the insertion of virtual lab practice as a part of a subject, have constituted interesting tools for both a teaching support and motivation encourage, in order to improve the students' learning.

It has been observed that the use of audiovisual materials as teaching tools motivate and encourage the students' learning, which has impacts on the marks obtained in the lab practices, because of the obvious improvement which has been found since this kind of materials is used. Furthermore, a decrease in the percentage of students who do not assist the lab practices was observed, which has a large impact on decreasing the desertion of the subject. Therefore, the videos constitute a complementary and useful tool, which facilitates the students' learning. However, they of course do not substitute their personal study work.

Regarding the virtual lab practice, the academic results obtained were similar to or better than those obtained in the face-to-face practice, despite the greater difficulty of virtual practice. Students highly valued the possibility of accessing the virtual lab practice at any time of the day, instead of attending a lab practice on a certain day and time, which allows them to organize their own time. After the experience of the two academic courses in which this practice has been used, the teachers' opinion regarding the implementation of virtual practices has been very positive, for long time and high cost practices, as well as practices that might represent a certain risk for the students, but always as a complement for face-to-face practices, but of course not as a substitute of them.

The teaching material developed can be used both in the pre-University studies in High School and in the first University year, depending on the level of learning required. Furthermore, the Chemistry Experimentation Virtual Lab in UPM contains a lab practice of chemical analysis of environmental samples, which could be applied to students of higher University years.

In our opinion, any effort carried out by the teachers in order to look for teaching tools and methodologies that may help to increase students' interest in Science in general and in Chemistry in particular, will be rewarded if a good level of learning of these subjects is achieved.

\section{Acknowledgements}

Authors acknowledge the support given by UPM, through different educational innovation project calls, all the teachers that concerns about improving the learning of their students, the supports given by the School of Civil Engineering of UPM, as well as all staff that have collaborated or facilitated the execution of the projects.

\section{REFERENCES}

[1] M.L. Casado, A. Carpeño, M.A. Castejón, M. Martínez, L. Sebastián (2012). Absentismo y abandono en primer curso de grado en la Universidad Politécnica de Madrid: Decálogo de prácticas para su reducción. II Conferencia Latinoamericana sobre el abandono en Educación Superior. Porto Alegre, Brasil.

[2] Real Decreto 1393/2007, de 29 de octubre, por el que se establece la ordenación de las enseñanzas universitarias oficiales. $B O E$, 30 de octubre de 2007, núm. 260, pp. 44037-44048.

[3] R. Torralba, R. Domínguez, M.A. Quijano, M.C. Heredia Una experiencia de CINE (Colaboración, Integración, Nivelación, Éxito). En Pinto Cañón G., Martín Sánchez M. (Eds.), Enseñanza y divulgación de la Química y la Física, 2012, pp. 357-361.

[4] Online Available: http://ocw.upm.es

[5] Online Available:

http://innovacioneducativa.upm.es/puestaapunto $\% 20 \mathrm{web} /$ por tada

[6] Proyecto de Innovación Educativa intercentro (IE PT105815144) (curso 2010-2011). Prácticas de Química en las titulaciones de Grado de la Universidad Politécnica de Madrid.

[7] Online Available: http://www.ice.upm.es/investigacion/giq/videos/ 
[8] S. García-Salgado, M.A. Quijano Nieto, R. Domínguez Gómez, M.C. Heredia Molinero, R. Torralba Marco. Videos: do they distract or inspire learning? Application to Chemistry lab of first university year. Proceedings of END2015 Conference $27^{\text {th }}-29^{\text {th }}$ June 2015, Porto, Portugal. ISBN: 978-989-99389-2-2, pp. 552-554.

[9] I. Carrillo, J. Albéniz, R. Barajas, P. Saavedra (2012) IX Jornadas Internacionales de Innovación Universitaria Retos y oportunidades del desarrollo de los nuevos títulos en educación superior.

[1] Online Available: http://innovacioneducativa.upm.es/ingeniamoselfuturo/juegos

[10] Online Available: $\mathrm{http} / / /$ innovacioneducativa.upm.es/documentos/proyectos/me moria transversales_2011_12.pdf

[11] Proyecto de Innovación Educativa intercentro (IE PT58029) (curso 2011-2012). Estrategias de Colaboración entre la Enseñanza Universitaria y las Enseñanzas Medias: Hacia la construcción de un espacio único, pp. 49-55.

[12] Online Available: http://innovacioneducativa.upm.es/trivial/quimica/juego/

[13] Online Available: http://innovacioneducativa.upm.es/trivial/quimica_en/juego/

[14] A. Carpeño, S. López, J. Arriaga (2014) Using Remote Laboratory eLab3D for a Broader Practical Skills Training in Electronics. Best Demo Award in REV2014 "International
Conference on Remote Engineering and Virtual Instrumentation".

[15] M. Berrocal-Lobo, A. Carpeño, A. De Antonio, C. Fernández, J. Ramírez, B. Recio, R. Torralba (2011) PEIA-UPM: Plataforma Experimental para Estudios en Ingeniería y Arquitectura de la UPM. Primer Congreso Internacional sobre Aprendizaje, Innovación y Competitividad (CINAIC 2011). Libro de actas del congreso (ISBN: 978-84-96398-50-4). Pag. 411-416.

[16] Online Available: http://3dlabs.upm.es/

[17] Online Available: https://youtu.be/LMQHoGBIU_0

[18] S. García-Salgado, R. Torralba Marco. Laboratorios virtuales: recurso didáctico aplicado a prácticas experimentales de análisis químico. TIC actualizadas para una nueva docencia universitaria. McGraw - Hill Education 2016, ISBN 978 $84-48612-65-8$, in press.

[19] J.R. Brinson (2015) Learning outcome achievement in non-traditional (virtual and remote) versus traditional (hands-on) laboratories: A review of the empirical research. Computers \& Education; 87: 218-237.

[20] S. García-Salgado, B. González Rodrigo, M.A. Quijano Nieto, R. Domínguez Gómez, M.C. Heredia Molinero, A. Martín Sanz, R. Torralba Marco. Strategies for encouraging vocations in Civil Engineering and Architecture. Proceedings of ICERI2015 Conference 16th-18th November 2015, Seville, Spain. ISBN: 978-84-608-2657-6, pp. 4068-4073. 